Free public transport: A socio-cognitive analysis

Peer-reviewed author version

COOLS, Mario; Fabbro, Yannick \& BELLEMANS, Tom (2016) Free public transport: A socio-cognitive analysis. In: TRANSPORTATION RESEARCH PART A-POLICY AND PRACTICE, 86, p. 96-107.

DOI: 10.1016/j.tra.2016.02.010

Handle: http://hdl.handle.net/1942/24008 


\title{
Free public transport: a socio-cognitive analysis
}

\author{
Mario Cools ${ }^{\mathrm{a}, \mathrm{b}, \mathrm{c}}$, Yannick Fabbro ${ }^{\mathrm{d}}$, Tom Bellemans ${ }^{\mathrm{d}}$ \\ ${ }^{a}$ University of Liège, ARGENCO, LEMA, Quartier Polytech 1, Allée de la Découverte 9, \\ Bât 52/3, 4000 Liège, Belgium \\ ${ }^{b}$ KULeuven Campus Brussels, Department of Informatics, Simulation and Modeling, \\ Warmoesberg 26, 1000 Brussels, Belgium \\ ${ }^{c}$ Hasselt University, Faculty of Business Economics, Agoralaan Gebouw D, 3590 \\ Diepenbeek, Belgium \\ ${ }^{d}$ Hasselt University, Transportation Research Institute (IMOB), Wetenschapspark 5, bus \\ 6, 3590 Diepenbeek, Belgium
}

\begin{abstract}
In this study, the modal shift potential of introducing a free alternative (free public transportation) and of changing the relative prices of transportation is examined. The influence of a cognitive analysis on the zero-price effect is also analyzed. The data used for the analysis stem from a stated preference survey with a sample of approximately 670 respondents that was conducted in Flanders, Belgium. The data are analyzed using a mixed logit model. The modeling results yield findings that confirm the existence of a zero-price effect in transport, which is in line with the literature. This zero-price effect is increased by the forced cognitive analysis for shopping trips, although not for work/school or recreational trips. The results also demonstrate the importance of the current mode choice in hypothetical mode choices and the importance of car availability. The influence of changing relative prices on the modal shift is found to be insignificant. This might be partially because the price differences were too small to matter. Hence, an increase in public transport use can be facilitated by the introduction of free public transport, particularly when individuals evaluate the different alternatives in a more cognitive manner. These findings should be useful to policy makers evaluating free public transport and considering how best to target and promote relevant policy.
\end{abstract}

Keywords: free public transport, socio-cognitive analysis, mixed logit model 
2

\section{Introduction}

Transportation has become extremely important in modern life. Everybody is, in some way, either directly or indirectly affected by transport. Its availability and accessibility delineate how, where and when we travel. Transport modal choice impacts many aspects of our lives, including our work, leisure and health (Kingham et al., 2001). The dependence on the car in everyday travel has increased enormously in recent decades, resulting in serious and growing consequences for the environment (e.g., greenhouse emissions) and health (e.g., casualties). Simultaneously, these consequences are very expensive for business (e.g., time lost due to congestion) and society (Brög et al., 2004). Growing concerns over these increasingly intolerable externalities have generated particular interest in how transport-planning policies might moderate the pressures resulting from growth in personal mobility and support the principles of sustainable development (Janssens et al., 2009; Cools et al., 2012). The problems concerning car use might be reduced in different ways. First, the negative impact of car use may be reduced via technological innovations that, e.g., increase the energy efficiency of cars or reduce the emissions per car kilometer. However, this type of policy tends to be overtaken by the continuing growth of motorized traffic worldwide. A second type of policy that has previously been very popular is the creation of new road infrastructure. This reduces congestion problems; however, environmental and health problems are likely to be exacerbated (Steg, 2003). A third type of policy is encouraging people to drive at other times or to other places. The fourth type of policy aims at reducing the level of car use by encouraging people to use other modes of transport, to combine trips, or to travel less. The fifth type of intervention aims at making people drive safer or in a more environmentally friendly manner (Steg, 2003).

This paper attempts to identify factors that influence an individual's mode choice by anticipating people's motivation to use other modes of transport and therefore can be framed in the fourth type of policy as described above. In this view, public transport (especially electric trains, trams and buses) appears to be a promising means of providing passenger transportation because it performs perhaps five or ten times better than cars in terms of energy per passenger-km (MacKay, 2009). Regardless, the car is more attractive than public transport because of its convenience, independence, flexibility, comfort, speed, and reliability and because driving is perceived to be more pleasurable (Steg, 2003). Another reason that it is so difficult 
to persuade people to use other travel modes instead of the car is the habitual character of the modal choices. Habits are formed when a behavior is repeated frequently in a stable context and leads to rewarding outcomes (Thøgersen, 2009). Nonetheless, there exists the potential to persuade people to switch to public transport when a set of circumstances are met. These circumstances include travel cost savings, frequency of service, time savings, accessibility to jobs, a variety of payment types, and the opportunity to do other things while traveling (Majumdar and Lentz, 2012). Other studies have indicated that travel choice is governed by a number of factors, most notably travel time and the availability of a car and of discounted long-term tickets and fares (Borndörfer et al., 2012). When one of these factors can be so powerful that it disrupts the context wherein habitual behavior is performed, progress can be made in influencing the modal split. In this context, the savings on travel cost, or travel fares, represents a factor in the modal choice worth investigating. Various studies (Kingham et al., 2001; Steg, 2003) have shown that the transportation price is one of the few evaluation factors where public transport can beat car transport. Fares are a direct and flexible instrument for influencing passenger behavior (Borndörfer et al., 2012). Therefore, to motivate people to use public transport, fares would need be lowered to a level whereby the traveler is enticed to choose public transport. This can be achieved by offering public transport at a reduced price or as free public transport. Nevertheless, free public transport to the user implies that a third party pays for the cost of provisioning (van der Vliet, 2010).

This paper examines the effect of transport at a reduced price and at a zero price. To investigate this effect, a respondent's actual (revealed) mode choice is compared $(i)$ with the mode choice knowing the genuine prices of transport, (ii) with the mode choice of the respondent when faced with reduced transport prices and (iii) with the mode choice of the respondent when the transport prices are further reduced such that public transport becomes free to the transport user.

\section{Literature Review}

\subsection{Zero-Price effect}

In this section, an explanation of the zero-price effect and some factors influencing the zero-price effect are provided. The word "free" has several meanings but essentially denotes that a product or service is made available at a zero price (Anderson, 2009). A free product used to be nothing more 
than an attention-grabbing marketing trick; however, under certain conditions, businesses can now obtain greater profits by giving products away than by charging for them. Smith (2008) indicated that when there is a voluntary exchange between two parties, both parties will benefit. Free is becoming a strategy that is essential for any company to survive. The success of a free product lies in the zero-price effect. The zero-price effect is an overreaction to a free product when people are faced with a choice between two products, of which one is free. This overreaction is to such an extent that the zero price means not only a low cost of buying the product but also an increased valuation of the product (Shampanier et al., 2007). People see zero as more than simply another price. The power of "free" also suggests that once a free item is priced above zero, the demand for that item could decrease significantly, namely by more than what conventional economics would predict (Leong and Lew, 2011). An explanation of this zero-price effect can be found in the mental transaction costs (Szabo, 1999). The mental transaction cost is a process that appears with every purchase of a priced product. The customer will ask himself whether this product is worth its price. In case of a free product, the lacking of this mental transaction cost makes it easier to convince people. The disadvantage of lacking a mental transaction cost is that there is no commitment and that people attach more value to products that they paid for (Szabo, 1999).

In prospect theory (Kahneman and Tversky, 1979), an explanation for the individual consumer choice behavior is examined. Prospect theory assumes that the choice process consists of two stages. In the preparation stage, the individual sets a reference point for a certain choice. In the evaluation stage, the outcome is compared to the reference point. The zero-price effect makes the reference point for relative thinking disappear (Nicolau, 2012). This disappearance creates a positive feeling within the consumer, who is used to making the decision concerning the purchase of a product. It has been suggested that this positive feeling is derived from the fact that the purchase implies only benefits, not costs. When this feeling is eliminated, the zero-price effect disappears.

The zero-price effect was examined for several products, including chocolates (Shampanier et al., 2007; Baumbach, 2011), telecommunication (Driouchi et al., 2011) and stereo systems (Baumbach, 2011). These studies generally confirm the zero-price effect. Especially in regard to simple decisions, the zero-price effect is found to be significant. In more complex decisions concerning more expensive products, a unilateral conclusion about 
the significance of the zero-price effect could not be found. Of all the possible explanations for the zero-price effect, the psychological mechanism affect was found to be the only significant such effect. This psychological mechanism ensures that options with no downside (no cost) invoke a more positive affective response, to the extent that consumers use this affective reaction as a decision-making cue to opt for the free option (Finucane et al., 2000; Gourville and Soman, 2005). Other psychological mechanisms, such as mapping difficulty, i.e., the difficulty consumers have with mapping the utility they expect to receive from hedonic consumption into monetary terms (Ariely et al., 2006), and social norm, i.e., the norm that consumers use when deciding over a free product, were not found to influence the zero-price effect significantly (Shampanier et al., 2007).

There is much controversy concerning the role of the affect mechanism in the decision-making process. Peine et al. (2009) proposed the Appraisal Theory of Lazarus. In this theory, cognition comes first in the decisionmaking process before the affect mechanism. This theory was confirmed in the study of Shampanier et al. (2007). This means that the positive feelings about the free product lead to an increased demand for the free product. This theory is in contrast to the theory of Zajonc $(1980,1984)$, in which it is stated that affect can be generated without the participation of cognition, which proves that affect should not precede cognition. This theory is supported by several studies (Baumbach, 2011; Driouchi et al., 2011). The strength of the influence of the affective and cognitive evaluation depends on the situation in which they occur, the focus during the decision, processing resources available in the decision-making process and the involvement of the decision maker (Baumbach, 2011).

\subsection{Zero-price effect in public transport}

Public transport fares are subject to a number of contradictory needs and requirements. On the one hand, the fares should be increased in response to, e.g., budgetary requirements and dividends to owners. On the other hand, there are strong pressures to keep fares low and subsidies high because people strongly value public transport; however, they consider it to be too expensive or infrequent to effectively replace private transport (Link and Polak, 2003). Objectives such as social inclusion, fairness, internalization of external benefits and corrections for underpriced private transport pull in the direction of lower fares (Fearnley, 2003). Fares can also have an impact on traffic safety. Although reductions in fares for public transport provide 
smaller direct safety benefits, they can have substantially larger impacts if they help create more transit-oriented communities, where residents tend to own fewer cars and drive less than they would otherwise (Litman, 2012).

Weis et al. (2010) computed price elasticities, therein suggesting that respondents are more sensitive to increases in public transport ticket prices than to rising fuel prices. Thus, it may be expected that an increase in the prices of public transport will result in a decrease in the demand for public transport (Witbreuk and De Jong, 2001). Therefore, fares are an important variable in terms of both the increase in usage as well as the improvement of the cost-benefit ratio. Several studies have been conducted on how certain determinants, such as price, affect modal choice. Thøgersen (2006) illustrated that motivation, past behavior and habits, opportunities or constraints regarding the use of public transport and car ownership determine the mode choice. A modification in fares can influence some of these determinants. A decrease in fares to zero may positively influence motivation because the zero-price effect will elicit positive feelings toward public transport (Shampanier et al., 2007). This will influence attitude, which powers the behavioral intention to use public transport (Ajzen, 1991).

In addition to the motivation, free public transport could increase the opportunities regarding the use of public transport. The study of Thøgersen (2006) indicated the importance of habits as a determinant of mode choice. Habits are a form of automaticity in responding that develops as people repeat actions under stable circumstances (Verplanken and Aarts, 1999; Verplanken and Wood, 2006). To change these habits, interventions can be applied upstream and downstream of the behavior (Verplanken and Wood, 2006). Downstream interventions aim at the avoidance of existing negative outcomes, whereas upstream interventions intent to avoid the outcome in the first place. Free public transport is an example of a downstream intervention; however, the study of Verplanken and Wood (2006) demonstrated that an economic incentive was only effective in the case of weakly habitual or non-habitual behavior, whereas mode choice typically is strongly habitual. These results contradict the study of Fujii and Kitamura (2003), where the effect of a temporary change in the level of service on habitual drivers was measured. The results showed that a structural change in the level of service (e.g., free bus ticket or temporary road capacity reduction) led to an increased usage of the public transport, which was sustained after the period of temporary, structural change. Moreover, the attitude toward public transport use was improved over that before the structural change, and the 
habitual behavior of car usage was reduced. De Witte et al. (2008) found a certain margin of growth in the usage of public transport when it becomes free; however, it should be combined with investments in the quality of public transportation (e.g., frequency, capacity, and connections). In the study of Boyd et al. (2003), the modal shift on the campus of the University of California at Los Angeles was examined after making bus transport free of charge. Transit ridership increased by more than 50\%, and more than 1000 fewer automobile trips were taken to the campus each day. De Witte et al. (2006) investigated the effects of free public transport for students in Brussels and found that public transport ridership increased when it was made free of charge, although they could not draw significant conclusions due to the lack of a control group. De Witte et al. (2006) also conducted a cost-benefit analysis, in which they illustrated that the introduction of free public transport can increase the social surplus as long as no more than $86 \%$ of the space made available on the road is filled up by new car users. Verheyen (2010) investigated the effect of free public transport on the modal split and made a distinction according to trip motives, i.e., trip purposes such as commuting, shopping and recreation. The results indicated that fares were significantly influential only in the case of shopping trips.

\section{Data and Methodology}

A stated preference survey was conducted to examine whether a price effect and/or a zero-price effect occurs among respondents in Flanders (the northern part of Belgium). The total population in 2010 amounted to 6.2 million inhabitants. An average Flemish respondent makes 2.8 trips a day. A total of $68 \%$ of these trips are made by car, followed by $12.28 \%$ by foot, $11.91 \%$ by bike, $2.71 \%$ by bus and $1.78 \%$ by train (Declercq et al., 2012).

Stated preference methods are widely accepted in travel behavior research and in particular for the identification of behavioral responses to choice situations that are not revealed in the market (Hensher, 1994). There has been some disagreement as to whether individuals' stated preferences closely correspond to their actual preferences (Kroes, 1986). Despite this disagreement, Wardman (1988) found evidence that individuals' stated preferences among hypothetical travel scenarios are a reasonably accurate guide to true underlying preferences. The SP-survey was conducted on a individual level from mid-November 2012 to late January 2013 and was completed by random individuals who are assumed to make their own transport decisions (over 17 
years of age). The survey was distributed over the Internet, thereby allowing flexible question ordering to be included in the survey. This flexible question ordering counters question order effects. Typically, question order effects result in differences in means and correlations for specific and general questions and are caused by changes in the placement of specific (general) questions relative to general (specific) questions in the survey (DeMoranville and Bienstock, 2003). In total, the survey collected valuable information from 670 respondents.

The stated preference questionnaire consisted of four parts: (i) socioeconomic questions about the respondent, (ii) questions about the respondent's transport situation, (iii) hypothetical modal choices and (iv) questions about fare evasion. The first part of the survey consisted of some socio-economic variables (e.g., gender, age, household situation, and income). In addition to the socio-economic variables, information about the respondent's transport situation was obtained (e.g., car availability and current used modes). In part three, the respondents have to indicate their modal preferences among a set of three alternatives with certain prices or tariffs. Each respondent was confronted with nine modal choices (3 price scenarios $\mathrm{x} 3$ trip motives), as displayed in Table 1 .

Table 1: Overview of the 9 price scenarios (prices expressed in Euros)

\begin{tabular}{lrlllllllll}
\hline & \multicolumn{3}{c}{ Scenario A } & \multicolumn{4}{c}{ Scenario B } & \multicolumn{5}{c}{ Scenario C } \\
& Car & PT & Bike & Car & PT & Bike & Car & PT & Bike \\
\hline Work/school trip & & & & & & & & & \\
Distance: $0-2.5 \mathrm{~km}$ & 1.00 & 0.50 & 0.60 & 0.75 & 0.25 & 0.35 & 0.50 & 0.00 & 0.10 \\
Distance: $2.6-5.0 \mathrm{~km}$ & 2.00 & 0.50 & 0.60 & 1.75 & 0.25 & 0.35 & 1.50 & 0.00 & 0.10 \\
Distance: $5.1-7.5 \mathrm{~km}$ & 3.00 & 0.50 & 0.60 & 2.75 & 0.25 & 0.35 & 2.50 & 0.00 & 0.10 \\
Distance: $7.6-10.0 \mathrm{~km}$ & 4.25 & 0.50 & 0.60 & 4.00 & 0.25 & 0.35 & 3.75 & 0.00 & 0.10 \\
Distance: $10.1-15.0 \mathrm{~km}$ & 6.00 & 0.50 & 0.60 & 5.75 & 0.25 & 0.35 & 5.50 & 0.00 & 0.10 \\
Distance: $15.1-20.0 \mathrm{~km}$ & 8.50 & 0.50 & 0.60 & 8.25 & 0.25 & 0.35 & 8.00 & 0.00 & 0.10 \\
Distance: $20.1-30.0 \mathrm{~km}$ & 12.00 & 0.50 & 0.60 & 11.75 & 0.25 & 0.35 & 11.50 & 0.00 & 0.10 \\
Distance: $30.1-50.0 \mathrm{~km}$ & 19.50 & 0.50 & 0.60 & 19.25 & 0.25 & 0.35 & 19.00 & 0.00 & 0.10 \\
Distance: $>50.0 \mathrm{~km}$ & 24.25 & 0.50 & 0.60 & 24.00 & 0.25 & 0.35 & 23.75 & 0.00 & 0.10 \\
\hline Shopping trip & & & & & & & & & \\
Distance: $5 \mathrm{~km}$ & 2.40 & 0.50 & 0.60 & 2.15 & 0.25 & 0.35 & 1.90 & 0.00 & 0.10 \\
\hline Leisure trip & & & & & & & & & \\
Distance: $15 \mathrm{~km}$ & 7.00 & 0.50 & 0.60 & 6.75 & 0.25 & 0.35 & 6.50 & 0.00 & 0.10 \\
\hline
\end{tabular}

In price scenario $\mathrm{A}$, the respondents were confronted with the actual transport prices. Actual prices for the car were determined using a study of De Ceuster (2004), who estimated a complete cost per kilometer (based 
on, e.g., fuel, net purchase vehicle, maintenance, insurance, and fuel tax). For a bike, a fixed cost was calculated based on the net purchase cost and the maintenance cost. The actual cost for the bus was estimated based on the subscription fee charged by the Flemish transport company. Because the subscription fee, as is the case for the costs for a bike, are fixed costs, the assumption was made that this mode was used on a (work) daily base. In price scenario B, the tariff for the public transport was halved. The tariffs for the other modes were decreased by the same amount (i.e., 0.25 Euros). In price scenario $\mathrm{C}$, the prices and tariffs were again decreased by the same amount, thereby making the public transport option free. This enables a measurement of the reaction to a price reduction toward a positive price as well as the reaction to the same price reduction toward a zero price. Each of these three price scenarios was investigated for three trip motives, i.e., work/school, shopping and recreation. For the work/school trip, a distancerelated cost is calculated for the car option based on the distance to work or school that the participants indicated. For the shopping trips, the cost for the car was based on a distance of approximately 5 kilometers to a shop. For the recreational trip, the cost for the car was based on a trip length of approximately 15 kilometers to the nearest cinema.

Table 2 gives an overview of the data types and the corresponding coding of the variables that were collected in the survey. Due to the large number of variables, only the variables that are included in the final models are presented here. Note that the relative cost is defined as the ratio of the cost of a given transport mode compared to the car cost as a function of the price scenarios (Table 1). For instance, for leisure trips under scenario A, the relative cost for car, public transport and bike are respectively 1 $(=7.00 / 7.00), 0.0714(=0.50 / 7.00)$, and $0.0857(=0.60 / 7.00)$.

Approximately half of the respondents (i.e., 348 of the 670 respondents) were subjected to a cognitive analysis. This cognitive analysis was assigned on a random basis (based on the month of birth) and was invoked immediately after the questions concerning the respondent's transport situation. Through this cognitive analysis, the participants were forced to engage in a cognitive and deliberate evaluation of the alternatives before making a decision, thereby making non-affective, more cognitive evaluations available and accessible. In particular, the participants were first asked to which degree they prefer to spend less for a random purchase. Consequently, the respondents were forced to make an internal comparison of the different modes. We assume that participants are more likely to base their evaluations on cog- 
Table 2: Overview of the variables collected in the survey with regard to modal choices

\begin{tabular}{|c|c|c|}
\hline Variable & Data type & Remarks (Coding) \\
\hline \multicolumn{3}{|r|}{ Socio-economic variables } \\
\hline Man_D2 & Categorical & 1 if man, 0 if woman \\
\hline Man_D3 & Categorical & 1 if man, 0 if woman \\
\hline Age_D2 & Numeric & Age of the respondent \\
\hline Age_D3 & Numeric & Age of the respondent \\
\hline Alone_D2 & Categorical & 1 if respondent lives alone, 0 otherwise \\
\hline Alone_D3 & Categorical & 1 if respondent lives alone, 0 otherwise \\
\hline Inc_D2 & Categorical & 1 if net monthly income of the respondent between $€ 0$ and $€ 1500,0$ otherwise \\
\hline Inc_D3 & Categorical & 1 if net monthly income of the respondent between $€ 0$ and $€ 1500,0$ otherwise \\
\hline IncNS_D2 & Categorical & 1 if net monthly income not specified, 0 otherwise \\
\hline IncNS_D3 & Categorical & 1 if net monthly income not specified, 0 otherwise \\
\hline Edu_D3 & Categorical & 1 if higher education (university/university college), $\mathrm{O}$ otherwise \\
\hline Urb_D2 & Categorical & Bike dummy: 1 if respondent lives in urban area, 0 otherwise \\
\hline \multicolumn{3}{|r|}{ Transport-related variables } \\
\hline DistHomeWS_D2 & Numeric & Distance between home and work \\
\hline DistHomeWS_D3 & Numeric & Distance between home and work \\
\hline CarAvail_D2 & Categorical & 1 if car is usually or always available, 0 otherwise \\
\hline CarAvail_D3 & Categorical & 1 if car is usually or always available, 0 otherwise \\
\hline CUWS_D1 & Categorical & 1 if respondent uses car for work/school trips currently, 0 otherwise \\
\hline CUWS_D2 & Categorical & 1 if respondent uses bike for work/school trips currently, 0 otherwise \\
\hline CUWS_D3 & Categorical & 1 if respondent uses public transport for work/school trips currently, 0 otherwise \\
\hline CUShop_D1 & Categorical & 1 if respondent uses car for shop trips currently, 0 otherwise \\
\hline CUShop_D2 & Categorical & 1 if respondent uses bike for shop trips currently, 0 otherwise \\
\hline CUShop_D3 & Categorical & 1 if respondent uses public transport for work/school trips currently, 0 otherwise \\
\hline CURecr_D1 & Categorical & 1 if respondent uses car for recreational trips currently, 0 otherwise \\
\hline CURecr_D2 & Categorical & 1 if respondent uses bike for recreational trips currently, 0 otherwise \\
\hline CURecr_D3 & Categorical & 1 if respondent uses public transport for recreational trips currently, 0 otherwise \\
\hline ExpPT_D3 & Categorical & 1 if respondent has experience with free public transport, 0 otherwise \\
\hline \multicolumn{3}{|r|}{ Modal choice variables } \\
\hline Bike_D2 & Categorical & 1 if mode is bike, 0 otherwise \\
\hline PT_D3 & Categorical & 1 if mode is public transport, 0 otherwise \\
\hline RelCostWS & Numeric & Prices and tariffs for the work/school motive relative to the car \\
\hline RelCostShop & Numeric & Prices and tariffs for the shopping motive relative to the car \\
\hline RelCostRecr & Numeric & Prices and tariffs for the recreational motive relative to the car \\
\hline Free & Categorical & 1 if mode is free, 0 otherwise \\
\hline
\end{tabular}

nitively available inputs under these conditions and therefore place a lower weight on the affective evaluations. Reliance on cognitive inputs should reduce the zero-price effect. Note that the cognitive analysis only marginally increased the average duration of the survey: respondents who undertook the cognitive analysis spent on average 10.9 minutes on the survey, in comparison to $10.2 \mathrm{~min}$ for those respondents who were not assigned to the cognitive analysis.

The descriptive statistics of the variables that are used in the models are displayed in Table 3. First, the dependent variables are displayed. The market shares for the different motives and the different price scenarios are displayed below, thereby demonstrating an explicit difference between the shares of the respondents who were subjected to the cognitive analysis and 
Table 3: Descriptive statistics

\begin{tabular}{|c|c|}
\hline Variable name & Description \\
\hline \multicolumn{2}{|l|}{ Dependent variables } \\
\hline \multirow{6}{*}{ Work/School mode choice } & Scenario $\mathrm{A}^{1}$ : Car: $36.00 \%$, Bike: $27.00 \%$, Public Transport: $37.00 \%$ \\
\hline & Scenario $\mathrm{A}^{2}$ : Car: $40.43 \%$, Bike: $26.85 \%$, Public Transport: $32.72 \%$ \\
\hline & Scenario B ${ }^{1}$ : Car: $33.33 \%$, Bike: $28.00 \%$, Public Transport: $38.67 \%$ \\
\hline & Scenario B ${ }^{2}$ : Car: $40.74 \%$, Bike: $27.78 \%$, Public Transport: $31.48 \%$ \\
\hline & Scenario C ${ }^{1}$ : Car: $32.67 \%$, Bike: $24.00 \%$, Public Transport: $43.33 \%$ \\
\hline & Scenario C $\mathrm{C}^{2}$ : Car: $37.96 \%$, Bike: $25.62 \%$, Public Transport: $36.42 \%$ \\
\hline & 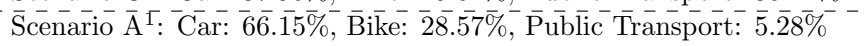 \\
\hline \multirow{4}{*}{ Shopping mode choice } & Scenario A ${ }^{2}$ : Car: $66.67 \%$, Bike: $28.16 \%$, Public Transport: $5.17 \%$ \\
\hline & Scenario B ${ }^{1}$ : Car: $64.91 \%$, Bike: $27.95 \%$, Public Transport: $7.14 \%$ \\
\hline & Scenario B ${ }^{2}$ : Car: $67.53 \%$, Bike: $27.59 \%$, Public Transport: $4.89 \%$ \\
\hline & Scenario $\mathrm{C}^{1}$ : Car: $62.42 \%$, Bike: $26.71 \%$, Public Transport: $10.87 \%$ \\
\hline & Scenario C $\mathrm{C}^{2}$ : Car: $64.08 \%$, Bike: $24.43 \%$, Public Transport: $11.49 \%$ \\
\hline & 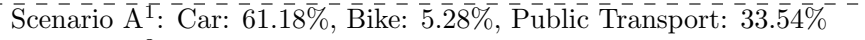 \\
\hline \multirow{5}{*}{ Recreational mode choice } & Scenario A ${ }^{2}$ : Car: $66.95 \%$, Bike: $5.75 \%$, Public Transport: $27.30 \%$ \\
\hline & Scenario B ${ }^{1}$ : Car: $61.18 \%$, Bike: $5.90 \%$, Public Transport: $32.92 \%$ \\
\hline & Scenario B ${ }^{2}$ : Car: $65.52 \%$, Bike: $6.61 \%$, Public Transport: $27.87 \%$ \\
\hline & Scenario C ${ }^{1}$ : Car: $57.76 \%$, Bike: $4.35 \%$, Public Transport: $37.89 \%$ \\
\hline & Scenario C ${ }^{2}$ : Car: $62.07 \%$, Bike: $5.17 \%$, Public Transport: $32.76 \%$ \\
\hline \multicolumn{2}{|c|}{ Independent variables: Socio-demographic characteristics } \\
\hline Gender & Female: $47.76 \%$, Male: $52.24 \%$ \\
\hline Age & Mean: 31, Standard Deviation: 15.41 \\
\hline Living situation & Alone: $12.09 \%$, Other: $87.91 \%$ \\
\hline Net monthly income & $\begin{array}{l}\text { Low (No Income and }<€ 1500 \text { ): } 57.91 \% \text {, High }(>€ 1500 \text { ): } 31.79 \% \text {, } \\
\text { Unspecified: } 10.30 \%\end{array}$ \\
\hline Education & University/University college: $41.64 \%$, Other: $58.36 \%$ \\
\hline Urbanization & No: $44.78 \%$, Yes (Urban): $55.22 \%$ \\
\hline \multicolumn{2}{|c|}{ Independent variables: Transport-related characteristics } \\
\hline Distance home-work/school & $\begin{array}{l}0-10 \mathrm{~km}: 41.35 \%, 10-20 \mathrm{~km}: 21.96 \%, 20-30 \mathrm{~km}: 17.95 \% \text {, } \\
30-50 \mathrm{~km}: 13.14 \%,>50 \mathrm{~km}: 5.61 \%\end{array}$ \\
\hline Car Availability & $\begin{array}{l}\text { Always: } 43.43 \% \text {, Usually: } 19.85 \% \text {, Sometimes: } 17.01 \% \text {, } \\
\text { Rarely: } 7.76 \% \text {, Never: } 11.94 \%\end{array}$ \\
\hline Current Use Work/school & Car: $43.43 \%$, Bike: $22.92 \%$, Public Transport: $29.33 \%$, Other: $4.32 \%$ \\
\hline Current Use Shopping & Car: $60.00 \%$, Bike: $24.48 \%$, Public Transport: $1.79 \%$, Other: $13.73 \%$ \\
\hline Current Use Recreational & Car: $57.76 \%$, Bike: $26.27 \%$, Public Transport: $5.67 \%$, Other: $10.30 \%$ \\
\hline Experience Free Public Transport & No: $1.94 \%$, Yes: $98.06 \%$ \\
\hline
\end{tabular}

those who were not. The following socio-demographic variables were considered: gender, age, living situation, income, education and urbanization. In addition, the following transport-related variables were considered: distance from home to work or school, car availability, the current use of modes for work or school trips, for shopping trips and for recreational trips and experience with free public transport.

Scenario $\mathrm{A}^{1}$ : Car: $36.00 \%$, Bike: $27.00 \%$, Public Transport: $37.00 \%$

Scenario B1. Car: $3333 \%$, Bike: $28.00 \%$, Public Transport: $38.67 \%$

Scenario A ${ }^{2}$ : Car: $66.67 \%$, Bike: $28.16 \%$, Public Transport: $5.17 \%$

Scenario B1: Car: $61.18 \%$, Bike: $5.90 \%$, Public Transport: $32.92 \%$

Scenario B ${ }^{2}$ : Car: $65.52 \%$, Bike: $6.61 \%$, Public Transport: $27.87 \%$

Scenario C ${ }^{2}$ : Car: $62.07 \%$, Bike: $5.17 \%$, Public Transport: $32.76 \%$

301 In terms of sample representativeness, the basic descriptive statistics presented in Table 3 correspond well to those reported in official travel behavior 
statistics (see, e.g., Declercq et al. (2012)). Nonetheless, the high share of respondents that experienced free public transport is noticeable but can be accounted for by the fact that the survey was conducted in a province (Limburg) where the largest city had adopted free public transport at the time of the survey.

The focus in this study lies on the assessment of whether the zero-price effect and price effect play a role in the transport decision process and of what other factors affect this decision. Each respondent had to indicate the preferred mode for a number of hypothetical situations. Therefore, a modeling approach that considers correlated responses for the choice among three or more categories is needed. The multinomial discrete choice procedure analyzes models wherein the choice set consists of multiple alternatives. This procedure supports conditional logit, mixed logit, heteroscedastic extreme value, nested logit, and multinomial probit models. The MDC procedure uses the maximum likelihood (ML) or simulated maximum likelihood method for model estimation. In this case, a mixed logit model is developed to estimate these relationships. As indicated by Hoffman and Duncan (1988), the mixed logit model is a combination of a multinomial logit and a conditional logit model. The multinomial logit focuses on the individual as the unit of analysis and uses the individual's characteristics as explanatory variables. The conditional logit focuses on the set of alternatives for each individual, and the explanatory variables are characteristics of those alternatives. A mixed logit model includes both characteristics of the alternatives and the individual. The corresponding choice probability can be written as

$$
\pi_{i j}=\frac{\exp \left\{\mathbf{x}_{i}^{\prime} \beta_{j}+\mathbf{z}_{i j}^{\prime} \gamma\right\}}{\sum_{k} \exp \left\{\mathbf{x}_{i}^{\prime} \beta_{k}+\mathbf{z}_{i k}^{\prime} \gamma\right\}},
$$

where $\mathbf{x}_{i}$ represents characteristics of the individuals that are constant across choices and $\mathbf{z}_{i j}$ represents characteristics that vary across choices (whether they vary by individual).

For each trip motive, three models were estimated to assess whether the price level and in particular the zero-price play a significant role in the modal decisions of the respondents: a model for all the respondents together (overall model) and a separate model for respondents who were subjected to the cognitive analysis and for those who were not subjected to the analysis. In addition to examining the effects of the zero-price and the prices, other personal and transport-related variables are included in the model to further 
explain the modal choices. Backward selection was used to find the most significant variables in the model. Backward selection removes variables from the model one at a time. Each variable included in the model is tested for removal at every step. The most insignificant variable is then removed from the model as long as its P-value remains above the significance level of 0.05 . Note that the key variables of interest were included in the final models, irrespective of their significance level. To evaluate the goodness-of-fit of the models, three commonly used pseudo $R^{2}$-values, i.e., McFadden's likelihood ratio index $R_{M}^{2}$, Estrella's alternative measure $R_{E_{2}}^{2}$, and Veall-Zimmermann's $R_{V Z}^{2}$, for which higher values indicate better model fit, were calculated.

\section{Results}

\subsection{Overall Results}

From Table 4, it can be concluded that the relative cost does not significantly affect the modal choice of the respondents. This is true for all trip motives considered in the study, is evidenced by the overall models as well as the group-specific models, and might be partially because the price differences were insignificant. On the other hand, the presence of a free alternative does affect the modal choice significantly for work/school (overall and non-cognitive model) and shopping trips (all three models). In addition, this effect is only borderline non-significant for the recreational motive (p-value between 0.05 and 0.10 for the overall model).

Concerning socio-economic variables, the different considered variables all play a role in the mode choice models; however, their respective impact is strongly dependent on the considered trip motive and group of respondents (overall, cognitive or non-cognitive). Education and the urban environment, in which the respondents live, have only a marginal role in the different models.

Regarding the transport-related variables, the longer the distance to work/school, the smaller the likelihood to bike, and the higher the likelihood to use public transport. Furthermore, car availability affects the choice for a bike significantly in the context of work/school and recreational trips and affects the choice for public transport significantly in all three trip motives. Moreover, the current (revealed) mode choice for the different trip motives has a significant impact on the stated mode choice. Finally, an experience with free public transport does affect the choice for public transport significantly 
Table 4: Direction and significance of the parameter estimates for the different modal choice models

\begin{tabular}{|c|c|c|c|c|c|c|c|c|c|}
\hline \multirow{2}{*}{ Parameter } & \multicolumn{3}{|c|}{ Work/school } & \multicolumn{3}{|c|}{ Shopping } & \multicolumn{3}{|c|}{ Recreation } \\
\hline & All & Cog. & Non-Cog. & All & Cog. & Non-Cog. & All & Cog. & Non-Cog. \\
\hline Bike_D2 & + & +++ & 0 & 0 & 0 & 0 & 0 & 0 & 0 \\
\hline PT_D3 & 0 & 0 & -- & -- & 0 & 0 & 0 & 0 & 0 \\
\hline RelCostWS & 0 & 0 & 0 & & & & & & \\
\hline RelCostShop & & & & 0 & 0 & 0 & & & \\
\hline RelCostRecr & & & & & & & 0 & 0 & 0 \\
\hline Free & ++ & 0 & + & +++ & +++ & ++ & + & 0 & 0 \\
\hline Age_D2 & ++ & & +++ & & & --- & ++ & & \\
\hline Age_D3 & ++ & & +++ & & +++ & -- & & & \\
\hline Man_D2 & & & & +++ & ++ & +++ & +++ & +++ & \\
\hline Man_D3 & & & & & & +++ & & --- & \\
\hline Alone_D2 & & & --- & & & & & & \\
\hline Alone_D3 & & & & +++ & +++ & +++ & +++ & & ++ \\
\hline DistHomeWS_D2 & --- & --- & --- & & & & & & \\
\hline DistHomeWS_D3 & +++ & +++ & ++ & & & & & & \\
\hline Inc_D2 & --- & --- & -- & +++ & & & ++ & & \\
\hline Inc_D3 & & & & & & & +++ & & +++ \\
\hline IncNS_D2 & --- & --- & & & -- & & & & \\
\hline IncNS_D3 & +++ & & +++ & & & & & & \\
\hline Edu_D3 & & & & & & & & -- & ++ \\
\hline Urb_D2 & & & & & & & -- & -- & \\
\hline CarAvail_D2 & --- & --- & & & & & --- & --- & --- \\
\hline CarAvail_D3 & --- & --- & & --- & --- & --- & --- & --- & --- \\
\hline CUWS_D1 & +++ & +++ & +++ & & & & & & \\
\hline CUWS_D2 & +++ & +++ & +++ & & & & & & \\
\hline CUWS_D3 & +++ & +++ & +++ & & & & & & \\
\hline CUShop_D1 & & & & +++ & +++ & +++ & & & \\
\hline CUShop_D2 & & & & +++ & +++ & +++ & & & \\
\hline CUShop_D3 & & & & +++ & ++ & 0 & & & \\
\hline CURecr_D1 & & & & & & & +++ & +++ & +++ \\
\hline CURecr_D2 & & & & & & & +++ & +++ & +++ \\
\hline CURecr_D3 & & & & & & & ++ & 0 & + \\
\hline ExpPT_D3 & +++ & & +++ & & & & ++ & & \\
\hline$R_{E_{2}}^{2}$ & 0.763 & 0.757 & 0.783 & 0.630 & 0.635 & 0.623 & 0.566 & 0.588 & 0.542 \\
\hline$R_{M}^{2}$ & 0.489 & 0.487 & 0.516 & 0.369 & 0.378 & 0.371 & 0.323 & 0.343 & 0.310 \\
\hline$R_{V Z}^{2}$ & 0.754 & 0.752 & 0.773 & 0.651 & 0.661 & 0.653 & 0.604 & 0.626 & 0.590 \\
\hline
\end{tabular}

for work/school trips (overall and non-cognitive model) and recreation trips (overall model).

\subsection{Parameter estimates}

The parameter estimates for the mixed (multinomial conditional) logit mode choice models are shown in Tables 5, 6 and 7. The most used way to interpret the parameter is by the sign and the magnitude of the parameters. 


\subsubsection{Work/school model}

In the overall work/school model (Table 5), the parameter that represents the zero-price effect has a positive sign. This implies an increased modal share for public transport when it is available for free. Parameter estimates from the cognitive and non-cognitive model show that the effect is larger for respondents that were not subjected to the cognitive analysis, albeit it should be noted that these estimates are only significant at the 0.10 level of significance. The distance between the home location and the work or school location has a negative sign for a bike and a positive sign for public transport. Thus, an increase in distance between the home location and the work or school location decreases the modal share of a bike and increases the modal share of public transport.

The income parameter of a bike has a negative sign. This implies that an increase in income significantly lowers the likelihood of using a bike when traveling to work or school. The car availability parameters of a bike and public transport also have a negative sign. This indicates a lower probability of choosing a bike and public transport when a car is usually or always available. The current use parameters show all three positive signs, which is quite logical. When a respondent uses a specific mode in daily life, the likelihood of choosing this specific mode increases in the hypothetical situations. This means that the respondent's choice in hypothetical situations depends partly on the current modal choice in daily life for a specific motive.

\subsubsection{Shopping model}

In the shopping models (Table 6), the parameters representing the zeroprice effect are positive, which suggests an increased probability of choosing public transport when it is made available for free. The magnitude of the parameter shows that the zero-price effect is more powerful for the shopping motive than for the work/school motive. Moreover, there is a difference in the zero-price effect for people who were subjected to a cognitive analysis and those who were not. The parameter estimate of the zero-price effect for the group that was subjected to the cognitive analyses was 1.133, whereas the parameter estimate of the zero-price effect for the group that was not subjected to the cognitive analyses was 0.634 . Thus, we can conclude that the zero-price effect is greater when people are forced to engage in a cognitive and deliberate evaluation of the alternatives before they make a decision and thereby make a less affective and more cognitive decision.

The gender parameters have a positive sign for the bike mode. This 
Table 5: Parameter estimates for the work/school modal choice models

\begin{tabular}{lrrrrrrrrr}
\hline \multirow{2}{*}{ Parameter } & \multicolumn{3}{c}{ All } & \multicolumn{4}{c}{ Cognitive } & \multicolumn{3}{c}{ Non-cognitive } \\
& Est. & S.E. & p-value & Est. & S.E. & p-value & Est. & S.E. & p-value \\
\hline Bike_D2 & 1.198 & 0.716 & 0.094 & 2.373 & 0.821 & 0.004 & -1.020 & 1.063 & 0.337 \\
PT_D3 & -1.084 & 0.677 & 0.110 & -0.178 & 0.922 & 0.847 & -2.066 & 0.934 & 0.027 \\
RelCostWS & -0.630 & 0.787 & 0.424 & -0.519 & 1.107 & 0.639 & -0.983 & 1.127 & 0.383 \\
Free & 0.365 & 0.147 & 0.013 & 0.337 & 0.205 & 0.100 & 0.401 & 0.219 & 0.068 \\
Age_D2 & 0.023 & 0.010 & 0.018 & & & & 0.058 & 0.015 & $<0.001$ \\
Age_D3 & 0.015 & 0.006 & 0.016 & & & & 0.026 & 0.009 & 0.004 \\
Alone_D2 & & & & & & & -1.152 & 0.369 & 0.002 \\
DistHomeWS_D2 & -0.308 & 0.057 & $<0.001$ & -0.368 & 0.079 & $<0.001$ & -0.269 & 0.085 & 0.002 \\
DistHomeWS_D3 & 0.132 & 0.038 & 0.001 & 0.160 & 0.053 & 0.003 & 0.134 & 0.056 & 0.017 \\
Inc_D2 & -1.284 & 0.297 & $<0.001$ & -1.184 & 0.314 & $<0.001$ & -1.068 & 0.444 & 0.016 \\
IncNS_D2 & -1.378 & 0.419 & 0.001 & -1.892 & 0.661 & 0.004 & & & \\
IncNS_D3 & 0.582 & 0.212 & 0.006 & & & & 1.125 & 0.291 & $<0.001$ \\
CarAvail_D2 & -0.851 & 0.264 & 0.001 & -1.012 & 0.361 & 0.005 & & & \\
CarAvail_D3 & -0.744 & 0.203 & $<0.001$ & -1.133 & 0.271 & $<0.001$ & & & \\
CUWS_D1 & 2.112 & 0.234 & $<0.001$ & 1.773 & 0.303 & $<0.001$ & 2.940 & 0.363 & $<0.001$ \\
CUWS_D2 & 2.968 & 0.221 & $<0.001$ & 2.842 & 0.317 & $<0.001$ & 3.930 & 0.395 & $<0.001$ \\
CUWS_D3 & 1.302 & 0.215 & $<0.001$ & 1.269 & 0.292 & $<0.001$ & 1.242 & 0.334 & $<0.001$ \\
ExpPT_D3 & 0.570 & 0.165 & 0.001 & & & & 0.963 & 0.245 & $<0.001$ \\
\hline D1,_D2,_D3 indicate application to & respectively the car, bike and public transport alternative
\end{tabular}

Table 6: Parameter estimates for the shopping modal choice models

\begin{tabular}{lrrrrrrrrr}
\hline \multirow{2}{*}{ Parameter } & \multicolumn{3}{c}{ All } & \multicolumn{3}{c}{ Cognitive } & \multicolumn{3}{c}{ Non-cognitive } \\
& Est. & S.E. & p-value & Est. & S.E. & p-value & Est. & S.E. & p-value \\
\hline Bike_D2 & -0.965 & 0.609 & 0.113 & 0.206 & 0.835 & 0.805 & -0.620 & 0.888 & 0.485 \\
PT_D3 & -1.231 & 0.619 & 0.047 & -1.441 & 0.899 & 0.109 & -1.261 & 0.944 & 0.182 \\
RelCostShop & 0.126 & 0.699 & 0.857 & 0.951 & 0.972 & 0.328 & -0.239 & 1.012 & 0.814 \\
Free & 0.841 & 0.194 & $<0.001$ & 1.133 & 0.281 & $<0.001$ & 0.634 & 0.275 & 0.021 \\
Age_D2 & & & & & & & -0.017 & 0.006 & 0.002 \\
Age_D3 & & & & 0.032 & 0.009 & 0.001 & -0.028 & 0.012 & 0.023 \\
Man_D2 & 0.387 & 0.115 & 0.001 & 0.326 & 0.154 & 0.035 & 0.485 & 0.171 & 0.005 \\
Man_D3 & & & & & & & 0.864 & 0.278 & 0.002 \\
Alone_D3 & 0.917 & 0.212 & $<0.001$ & 1.049 & 0.315 & 0.001 & 0.809 & 0.301 & 0.007 \\
Inc_D2 & 0.499 & 0.121 & $<0.001$ & & & & & & \\
IncNS_D2 & & & & -0.636 & 0.303 & 0.036 & & & $<0.001$ \\
CarAvail_D3 & -1.427 & 0.202 & $<0.001$ & -1.762 & 0.329 & $<0.001$ & -1.298 & 0.329 & $<0.001$ \\
CUShop_D1 & 1.072 & 0.139 & $<0.001$ & 1.107 & 0.197 & $<0.001$ & 1.028 & 0.201 & $<0.001$ \\
CUShop_D2 & 1.092 & 0.151 & $<0.001$ & 1.112 & 0.220 & $<0.001$ & 1.206 & 0.212 & $<0.001$ \\
CUShop_D3 & 1.102 & 0.383 & 0.004 & 1.503 & 0.665 & 0.024 & 0.471 & 0.522 & 0.367 \\
\hline D1,_D2,_D3 indicate application to respectively the car, bike and public transport alternative
\end{tabular}

means that men have a significantly higher probability of choosing a bike for the shopping motive compared to women. The living situation parameters have a positive sign for the public transport option. This indicates a higher probability of choosing public transport for the shopping motive when people 
live alone compared to people who do not live alone. The car availability parameters associated with the public transport choice have a negative sign. This indicates a lower probability of choosing public transport when a car is usually or always available. The three current use parameters all show positive signs, which is logical. When a respondent uses a specific mode in daily life for shopping trips, the probability of choosing this specific mode increases. This indicates that the likelihood of choosing a specific mode is enhanced when this mode is used in daily life for these motives. When we compare these parameters with the daily use parameters of the work/school motive, we see that these parameters are lower. This means that the modal choices depend to a lesser extent on the current use of modes for the shopping motive compared to the work/school motive.

\subsubsection{Recreation model}

The parameter representing the zero-price effect in the overall model (Table 7 ) has a positive sign but is only significant at the 0.10 level of significance. In contrast, in the cognitive and non-cognitive model, the zero-price effect was not significant.

The age parameter concerning a bike has a positive sign in the overall model, which implies that the probability of choosing a bike as the mode of transport for recreational trips increases with increasing age. The gender parameter has a positive sign for the bike mode (in the overall and cognitive model). This means that men exhibit a significantly higher probability for choosing a bike for the recreational motive compared to women. The living situation parameter shows a positive sign for public transport (in the overall and non-cognitive model). This means that people who are living alone are more inclined to use public transport for recreational trips than are people who do not live alone. This parameter is smaller than for the shopping motive; therefore, the effect of living situation is less distinct than for the shopping model.

The parameter that includes whether the respondent lives in a urban environment shows a negative sign for the use of a bike (in the overall and cognitive model). This implies that people are less inclined to use a bike for recreational trips when they live in urban environments. The car availability parameters of a bike and public transport show a negative sign. This means that there is a lower probability of choosing a bike and public transport when a car is usually or always available. Car availability has the greatest influence on bike use for shopping trips, followed by recreational trips, and 
Table 7: Parameter estimates for the recreational modal choice models

\begin{tabular}{|c|c|c|c|c|c|c|c|c|c|}
\hline \multirow{2}{*}{ Parameter } & \multicolumn{3}{|c|}{ All } & \multicolumn{3}{|c|}{ Cognitive } & \multicolumn{3}{|c|}{ Non-cognitive } \\
\hline & Est. & S.E. & $\mathrm{p}$-value & Est. & S.E. & $\mathrm{p}$-value & Est. & S.E. & $\mathrm{p}$-value \\
\hline Bike_D2 & -1.884 & 2.612 & 0.471 & -2.763 & 3.577 & 0.440 & -1.005 & 3.696 & 0.786 \\
\hline PT_D3 & 0.945 & 2.567 & 0.713 & 0.033 & 3.558 & 0.993 & 0.553 & 3.689 & 0.881 \\
\hline RelCostRecr & 1.538 & 2.703 & 0.570 & -0.331 & 3.752 & 0.930 & 1.162 & 3.888 & 0.765 \\
\hline Free & 0.317 & 0.169 & 0.060 & 0.251 & 0.236 & 0.287 & 0.280 & 0.242 & 0.247 \\
\hline Age_D2 & 0.018 & 0.009 & 0.048 & & & & & & \\
\hline Man_D2 & 0.712 & 0.221 & 0.001 & 1.159 & 0.337 & 0.001 & & & \\
\hline Man_D3 & & & & -0.435 & 0.148 & 0.003 & & & \\
\hline Alone_D3 & 0.402 & 0.147 & 0.006 & & & & 0.419 & 0.202 & 0.038 \\
\hline Inc_D2 & 0.807 & 0.317 & 0.011 & & & & & & \\
\hline Inc_D3 & 0.339 & 0.115 & 0.003 & & & & 0.612 & 0.174 & $<0.001$ \\
\hline Edu_D3 & & & & -0.401 & 0.156 & 0.010 & 0.382 & 0.161 & 0.018 \\
\hline Urb_D2 & -0.405 & 0.204 & 0.047 & -0.673 & 0.287 & 0.019 & & & \\
\hline CarAvail_D2 & -0.949 & 0.256 & $<0.001$ & -0.908 & 0.297 & 0.002 & -0.973 & 0.325 & 0.003 \\
\hline CarAvail_D3 & -0.611 & 0.120 & $<0.001$ & -0.625 & 0.166 & $<0.001$ & -0.633 & 0.169 & $<0.001$ \\
\hline CURecr_D1 & 0.614 & 0.112 & $<0.001$ & 0.749 & 0.161 & $<0.001$ & 0.573 & 0.159 & $<0.001$ \\
\hline CURecr_D2 & 1.149 & 0.220 & $<0.001$ & 1.333 & 0.306 & $<0.001$ & 1.066 & 0.324 & 0.001 \\
\hline CURecr_D3 & 0.503 & 0.215 & 0.019 & 0.334 & 0.307 & 0.277 & 0.527 & 0.305 & 0.084 \\
\hline ExpPT_D3 & 0.293 & 0.124 & 0.018 & & & & & & \\
\hline
\end{tabular}

has the smallest influence on work/school trips. In addition, car availability has greater influence on public transport use for work/school trips than for recreational trips. The current use parameters of the car, bike and public transport modes show positive signs. This indicates that the likelihood of choosing a specific mode is enhanced when this mode is used in daily life for these motives. The parameter that represents the experience with free public transport shows a positive sign (in the overall model). This indicates that the probability of choosing public transport is enhanced after experiencing free public transport.

\section{Discussion}

In the previous sections, it was shown that the relationship between the relative prices and the modal choices were not significant at a 0.05 level. The absence of this relationship between prices of transport and modal choices is in contrast to the studies of De Witte et al. (2008) and Paulley et al. (2006). A possible reason for the absence of this relationship could be that the absolute differences in prices of the different scenarios were insignificant, i.e., a $€ 0.25$ difference between scenarios; thus, the difference might not have been clear to the respondents. 
In contrast to the study of Verheyen (2010), where only a zero-price effect for the shopping motive was found, a zero-price effect is found for the work/school motive and the shopping motive. The zero-price effect for the recreational motive was found to be insignificant at the 0.05 level but significant at the 0.10 level. These findings are in accordance with the revealed preference study for students conducted by De Witte et al. (2006), which indicated the modal shift potential of free public transport. The cognitive analysis, which was presented to $51.9 \%$ of the participants, had an unexpected effect on the zero-price effect for the shopping motive. The study of Shampanier et al. (2007) demonstrated that reliance on cognitive inputs should reduce the zero-price effect. Thus, the group that was subjected to a forced cognitive analysis was expected to show a reduced zero-price effect. This study shows a larger zero-price effect in the group that was subjected to a forced cognitive analysis. Therefore, we can conclude that the zero-price effect is not driven by the psychological construct affect in this modal choice study.

With respect to the socio-economic variables, different factors influence the modal choices depending on the trip motive that is considered and depending on which group of respondents is analyzed. Regarding the transportrelated parameters, one can observe that the transport-related parameters exhibit a larger influential nature compared to the socio-economic variables according to the magnitude of these parameters. The variable with the largest explanatory power is the current (revealed) use of modes. This variable represents the transport modes that the participants currently use for the different types of trips. The biggest influence of the current use variable is exerted on the work/school motive, followed by the shopping motive and then the recreational motive. This indicates that habitual behavior plays a role in this decision-making process. There is evidence that individuals at least have a strong tendency to "recycle" a decision made in the past when making travelmode choices (Thøgersen, 2006). When a decision is repeated several times per week in a stable context while obtaining the same outcome every time, it is unlikely that much reasoning is involved, and it seems highly likely that habitual processes are active in that decision-making process (Wood et al., 2002). This explains the strength of the explanatory power of the current use variable in the different scenarios. The greater number of times the decision is repeated in a stable context, the larger the influence of habitual behavior, and the larger the parameter estimates of the current use variable. For this reason, the parameter estimate of the current use variable is higher for the 
work/school motive than for the shopping motive and the recreational motive. A strong habit to use a particular travel mode is, in comparison with a weak habit, characterized by seeking less information and by a less elaborate choice of travel mode (Aarts et al., 1997; Verplanken et al., 1997). According to this view of habit, a strong habit is perceived to block the more deliberate, cognitive processing prior to behavior (Eriksson et al., 2008). This could be an explanation for the larger zero-price effect with participants subjected to a cognitive analysis for the shopping motive. This is because this cognitive evaluation makes a more deliberate, cognitive processing available for the participants, which in turn causes the decision making to be more based on cognitive reasoning instead of habitual behavior. This theory was also confirmed by Eriksson et al. (2008). This cognitive evaluation, wherein the car user evaluates the different features of his/her trip, will not automatically lead to a change in behavior. This evaluation can lead to a continuation of current behavior;h however the choice will be more influenced by personal norms and less by habitual behavior.

Another important transport-related parameter is car availability. In this model, the availability of a car significantly decreases the probability of using a bike or public transport in almost all models. This is because the availability of a private car in the household facilitates the choice of car transport and thereby reduces the likelihood of choosing other modes (Thøgersen, 2006). This is because car owners have more alternatives than does someone without a car and because habitual processes are more important than attitudes for car owners (Thøgersen, 2006). The variable including experience with free public transport has a positive influence on public transport use, which is in accordance with the literature. In a study of Fujii and Kitamura (2003), an experiment in which a one-month-free bus ticket was given to an experimental group was performed. The results showed that attitudes toward bus transport were more positive and that the frequency of bus use increased, whereas the habits of using automobiles decreased after the intervention, even one month after the intervention period. The implications of the variables including the distance between home and work or school and the urban environment are quite logical because the probability of using a bike decreases when travel distance increases. This produces a modal shift toward other modes such as public transport. Living in an urban environment reduces the likelihood of choosing a bike because there are numerous public transport options in an urban environment and because the safety of biking is lower in urban environments. 


\section{Policy recommendations}

The findings in this paper provide insight into the success and application of a measure concerning travel demand that aims at changing travel behavior. The modal split potential of the introduction of public transport at a reduced and at zero price was examined. A zero-price effect was found for the work/school motive and the shopping motive at a $5 \%$ significance level and for the recreational motive at a $10 \%$ significance level. This implies that the use of public transport will increase significantly when it is provided for free, and a change in relative prices does not provoke significant changes in the modal split because of the insignificance of the price effect. Thus, the subsidizing of public transport with the aim of making it free seems to be an effective measure to increase the use of public transport. Subsidizing public transport with the aim of making it less expensive or to change the relative prices with regard to car usage does not seem to be an appropriate measure for policy makers. Important obstacles to the success of such a policy measure are the current use of modes for different motives and car availability. The magnitude of the explanatory power of the current use variable in explaining the modal choices indicates that individuals have a strong tendency to recycle a decision made in the past. A policy measure that can counteract this recycling of decisions is the creation of a deliberate, cognitive process prior to the specific behavior. This can be accomplished by informational campaigns that raise awareness of the different characteristics of a trip, including price or tariffs. Additionally, car availability plays an important role in modal choices and may counteract the zero-price effect. To overcome this obstacle, policy makers must convince car owners to exchange car usage for public transport. Actions by the Flemish government, where a license plate can be exchanged for a free bus pass, have been demonstrated to be successful. Thus, combinations of policies with free public transport can further reduce car availability and increase the market share of public transport.

\section{Conclusions and further research}

This study investigated the impact of public transport at a reduced and zero price on the modal shares for individuals in Flanders, Belgium. The results from a mixed logit model indicate that people are not influenced by changing relative prices; however, the results show a significantly different modal split when free public transport is added to the range of alternatives. 
This zero-price effect was found to be more significant when individuals are first subject to a cognitive analysis, wherein participants are forced to engage in a cognitive and deliberate evaluation of the alternatives. This research finding can be considered by policy makers to increase the success of the implementation of free public transport. The key variables influencing mode choice appear to be the current use of modes and car availability. Both variables indicate the importance of habitual behavior and large commitments such as residential location choice, which should be considered by policy makers when they want to change choice behavior. However, for further research, the absolute value differences and budget changes can be increased to measure whether a price effect can be observed. This is because it is plausible that price does affect modal choices. Furthermore, developing a revealed preference experiment testing the zero-price effect using a sample in which all sections of the population are represented represents an intriguing study. To our knowledge, revealed preference experiments have only been performed for specific sections of the population in Flanders (such as students).

\section{Acknowledgments}

The authors express their gratitude for the constructive feedback of two anonymous reviewers.

\section{References}

Aarts, H., Verplanken, B., van Knippenberg, A., 1997. Habit and information use in travel mode choices. Acta Psychologica 96, 1-14.

Ajzen, I., 1991. The theory of planned behavior. Organizational Behavior and Human Decision Processes 50, 179-211.

Anderson, C., 2009. Free: The Future of a Radical Price. Hyperion, London.

Ariely, D., Gneezy, U., Haruvy, E., 2006. Social norms and the price of zero. Working Paper. MIT. Boston, MA.

Baumbach, 2011. The Zero-Price Effect - Its Relation to Price Affect and Price-Quality Inferences Regarding Low- and High-Priced Products. Master's thesis. Universitt Wien. Vienna, Austria. 
Borndörfer, R., Karbstein, M., Pfetsch, M.E., 2012. Models for fare planning in public transport. Discrete Applied Mathematics 160, 2591-2605.

Boyd, B., Chow, M., Johnson, R., Smith, A., 2003. Analysis of effects of fare-free transit program on student commuting mode shares: Bruingo at university of california at los angeles. Transportation Research Record: Journal of the Transportation Research Board 1835, 101-110.

Brög, W., Erl, E., Mense, N., 2004. Indiviualised marketing changing travel behaviour for a better environment, in: Communicating Environmentally Sustainable Transport The Role of Soft Measures: The Role of Soft Measures, OECD, Paris, France. pp. 83-97.

Cools, M., Brijs, K., Tormans, H., De Laender, J., Wets, G., 2012. Optimizing the implementation of policy measures through social acceptance segmentation. Transport Policy 22, 80-87.

De Ceuster, G., 2004. Internalisation of external costs of road traffic in Flanders. Technical Report MIRA/2004/04. Vlaamse Milieumaatschappij MIRA. Mechelen, Belgium. Original dutch title: "Internalisering van externe kosten van wegverkeer in Vlaanderen".

De Witte, A., Macharis, C., Lannoy, P., Polain, C., Steenberghen, T., Van de Walle, S., 2006. The impact of "free" public transport: The case of brussels. Transportation Research Part A: Policy and Practice 40, 671-689.

De Witte, A., Macharis, C., Mairesse, O., 2008. How persuasive is "free" public transport?: A survey among commuters in the brussels capital region. Transport Policy 15, 216-224.

Declercq, K., Janssens, D., Wets, G., 2012. Travel Behavior Research Flanders 4.3 (2010-2011): Table Report. Technical Report. Hasselt University. Diepenbeek, Belgium.

DeMoranville, C.W., Bienstock, C.C., 2003. Question order effects in measuring service quality. International Journal of Research in Marketing 20, $217-231$.

Driouchi, A., Chetioui, Y., Baddou, M., 2011. How Zero price Affects Demand? Experimental Evidence from the Moroccan Telecommunication Market. MPRA Paper 32352. 
Eriksson, L., Garvill, J., Nordlund, A.M., 2008. Interrupting habitual car use: The importance of car habit strength and moral motivation for personal car use reduction. Transportation Research Part F: Traffic Psychology and Behaviour 11, 10-23.

Fearnley, N., 2003. Inventive Pricing of Urban Public Transport. TØI report 655/2003. Institute of Transport Economic. Oslo, Norway.

Finucane, M.L., Alhakami, A., Slovic, P., Johnson, S.M., 2000. The affect heuristic in judgments of risks and benefits. Journal of Behavioral Decision Making 13, 1-17.

Fujii, S., Kitamura, R., 2003. What does a one-month free bus ticket do to habitual drivers? an experimental analysis of habit and attitude change. Transportation 30, 81-95.

Gourville, J.T., Soman, D., 2005. Overchoice and assortment type: When and why variety backfires. Marketing Science 24, 382-395.

Hensher, D.A., 1994. Stated preference analysis of travel choices: the state of practice. Transportation 21, 107-133.

Hoffman, S.D., Duncan, G.J., 1988. Multinomial and conditional logit discrete-choice models in demography. Demography 25, 415-427.

Janssens, D., Cools, M., Moons, E., Wets, G., Arentze, T., Timmermans, H., 2009. Road pricing as an impetus for environment-friendly travel behavior. Transportation Research Record: Journal of the Transportation Research Board 2115, 50-59.

Kahneman, D., Tversky, A., 1979. Prospect theory: An analysis of decision under risk. Econometrica 47, 263-292.

Kingham, S., Dickinson, J., Copsey, S., 2001. Travelling to work: will people move out of their cars. Transport Policy 8, 151-160.

Kroes, E., 1986. The use of attitude models and stated preference models in practical transport analysis, in: Behavioural Research for Transport Policy. VNU Science Press, Utrecht, Netherlands, pp. 307-326. 
Leong, W.Y., Lew, Y.D., 2011. A behavioural perspective to managing traffic congestion in singapore, in: Low, D. (Ed.), Behavioural Economics And Policy Design. World Scientific Publishing, Singapore, pp. 53-67.

Link, H., Polak, J., 2003. Acceptability of transport pricing measures among public and professionals in europe. Transportation Research Record: Journal of the Transportation Research Board 1839, 34-44.

Litman, T., 2012. Pricing for traffic safety: How efficient transport pricing can reduce roadway crash risk. Transportation Research Record: Journal of the Transportation Research Board 2318, 16-22.

MacKay, D.J.C., 2009. Sustainable Energy Without the Hot Air. IUT, Cambridge.

Majumdar, S.R., Lentz, C., 2012. Individuals' attitudes toward public transit in a rural transit district. Public Works Management \& Policy 17, 83-102.

Nicolau, J.L., 2012. Battle royal: Zero-price effect vs relative vs referent thinking. Marketing Letters 23, 661-669.

Paulley, N., Balcombe, R., Mackett, R., Titheridge, H., Preston, J., Wardman, M., Shires, J., White, P., 2006. The demand for public transport: The effects of fares, quality of service, income and car ownership. Transport Policy 13, 295-306.

Peine, K., Heitmann, M., Herrmann, A., 2009. Getting a feel for price affect: A conceptual framework and empirical investigation of consumers' emotional responses to price information. Psychology and Marketing 26, 39-66.

Shampanier, K., Mazar, N., Ariely, D., 2007. Zero as a special price: The true value of free products. Marketing Science 26, 742-757.

Smith, A., 2008. An Inquiry into the Nature and Causes of the Wealth of Nations: A Selected Edition. Oxford Paperbacks, Oxford, UK.

Steg, L., 2003. Can public transport compete with the private car? IATSS Research 27, 27-35.

Szabo, N., 1999. Micropayments and mental transaction costs, in: 2nd Berlin Internet Economics Workshop, Berlin, Germany. 
Thøgersen, J., 2006. Understanding repetitive travel mode choices in a stable context: A panel study approach. Transportation Research Part A: Policy and Practice 40,621-638.

Thøgersen, J., 2009. Promoting public transport as a subscription service: Effects of a free month travel card. Transport Policy 16, 335-343.

Verheyen, G., 2010. Irrationality in modal choices: Free public transport. Master's thesis. Hasselt University. Diepenbeek, Belgium. Original dutch title: "Irrationaliteit in Vervoerswijzekeuze: Gratis".

Verplanken, B., Aarts, H., 1999. Habit, attitude, and planned behaviour: Is habit an empty construct or an interesting case of goal-directed automaticity? European Review of Social Psychology 10, 101-134.

Verplanken, B., Aarts, H., Van Knippenberg, A., 1997. Habit, information acquisition, and the process of making travel mode choices. European Journal of Social Psychology 27, 539-560.

Verplanken, B., Wood, W., 2006. Interventions to break and create consumer habits. Journal of Public Policy \& Marketing 25, 90-103.

van der Vliet, S., 2010. "Free" public transport: Social costs and benefits of "free" public transport in Dutch cities. Lambert Academic Publishing.

Wardman, M., 1988. A comparison of revealed preference and stated preference models of travel behaviour. Journal of Transport Economics and Policy 22, 71-91.

Weis, C., Axhausen, K.W., Schlich, R., Zbinden, R., 2010. Models of mode choice and mobility tool ownership beyond 2008 fuel prices. Transportation Research Record: Journal of the Transportation Research Board 2157, 8694.

Witbreuk, M., De Jong, L., 2001. The Use and Efficiency of Public Transport : The Effects of Price and Service Measures. Thredbo 7. Institute of Transport and Logistics Studies. Sydney.

Wood, W., Quinn, J.M., Kashy, D.A., 2002. Habits in everyday life: thought, emotion, and action. Journal of personality and social psychology 83, 12811297. 
738

Zajonc, R., 1980. Feeling and thinking: Preferences need no inferences. American Psychologist 35, 151-175.

Zajonc, R.B., 1984. On the primacy of affect. American Psychologist 39, $117-123$. 